\title{
Unpacking developmental local government using Soft Systems Methodology and MCDA tools
}

\author{
L Scott* \\ Received: 9 November 2004; Revised: 16 August 2005; Accepted: 10 October 2005
}

\begin{abstract}
This paper presents two different analytical approaches that may be useful in developing an understanding of developmental local government (DLG). DLG implies a significant commitment with respect to poverty relief at the local administrative level as well as strong emphasis on participation and accountability to communities ${ }^{1}$. This paper attempts to apply Soft Systems Methodology (SSM) to clarify the activities that DLG implies for local authorities and focuses specifically on their ability to be developmental and to effectively impact upon poverty. An expected product of this approach will be the identification of specific indicators of (inter alia) poverty that may be used to monitor the effectiveness of local government from a constitutional and developmental perspective. Indicators may also be generated from the perspective of community needs and this paper reports on a case study which identifies the needs of a small community, Pniel, in the South African Western Cape, using a MultiCriteria Decision Analysis approach. This approach allows for both the identification and prioritisation of issues from the perspective of the community. Further, it is suggested that the SSM approach can be used to provide a context within which community needs may be considered. This framework clarifies what it is that local government have the aims, powers and functions to perform. Viewing the community needs within this framework provides a mechanism for realistically linking the community needs to the local authority's budget. A process of ongoing monitoring and evaluation of DLG, using the two sets of indicators, can assist to focus the functioning of local government on effective poverty relief.
\end{abstract}

Key words: Developmental local government, soft systems methodology, multiple criteria decision analysis, integrated development planning.

\section{Introduction and background}

Poverty is a world-wide phenomenon, the most obvious manifestation of which is a lack of wealth, income or assets with which to secure a comfortable or acceptable lifestyle.

\footnotetext{
*Department of Statistical Sciences, University of Cape Town, Private Bag, Rondebosch, 7700, South Africa, email: leanne@stats.uct.ac.za

1 "Developmental Government is local government committed to working with citizens within the community to find sustainable ways to meet their social, economic, and material needs and improve the quality of their lives.", White Paper on Local Government, March 1998.
} 
According to the World Development Report (2001) some $45 \%$ of the world's population live in poverty (exist on $<\$ 2$ per day). This statistic is made more concrete when we consider that the report also indicates that:

- approximately $30 \%$ of children younger than 5 are malnourished;

- in rich countries 1 child in 100 does not live to see their fifth birthday, whereas in poor countries this figure rises to 1 in 5 ;

- $32 \%$ of women over the age of 15 are illiterate.

The above statistics give some idea of the fact that poverty is not only a lack of money, but a multifaceted lack of power, voice, opportunity and security. Although many development agencies, such as the World Bank and the United Nations Development Program (UNDP), give credibility to the fact that poverty is indeed multidimensional, the most common approach to identifying the poor is through monetary indicators such as income or expenditure. A closer examination of the economics of poverty reveals that poverty is, however, not simply a shortage of money which could be resolved if that money were available or made available. The amount that many countries spend on poverty relief and social assistance programmes far exceeds the quantity $x$, where

$$
x=\sum_{i=1}^{q}\left(z-y_{i}\right),
$$

where $z$ is some poverty line, $y_{i}$ is the income of the $i$-th poor person and $q$ is the number of poor persons with income $z$ (UNDP, 2005). The amount of money that many countries spend on poverty relief and social assistance programmes far exceeds the quantity $x$, where $x$ is the actual amount of money required to completely eradicate poverty, given perfect information (Sen, 1981). Here 'eradicate poverty' means that those persons who were previously defined to be poor in terms of falling below some poverty line, would now no longer be so.

It seems clear from the above that poverty cannot be adequately described or explained in purely economic terms. (See, for example, Thomas et al. (2000) who include a discussion on the inadequacy of income as a measure of the quality of growth and development; and the discussion on "Beyond GNP" in Henderson (1991))

We thus are left with the fact that the intractability of poverty is at least in part due to inadequate systems of delivery; inadequate systems of information (of who and where the poor are) and a lack of political will to fundamentally change the status quo. It therefore makes sense to focus our attention specifically on those systems of delivery, of monitoring and, more fundamentally, of governance.

\section{Poverty and government}

We start with the premise that the existence of poverty relates at least in some part to poor governance. Thus in our attempts to understand poverty and its persistence it may 
be helpful to explore and articulate a model of the prevailing system of government. The South African government, along with many other governments that signed the agreements of the World Summit for Social Development in Copenhagen in 1995, as well as in Geneva in 2000, committed itself to reducing poverty. In South Africa it is constitutionally underwritten that local government should play a key role in poverty reduction in an approach referred to as Developmental Local Government (DLG). Because South Africa has adopted the notion of DLG which places local authorities at the forefront of poverty relief ${ }^{2}$, the focus of this study is on government at the local level. There is a wealth of writing governing the functioning of local government that richly describes the aspirations for this sphere of government. It is argued here that what is required is a stark unbundling of the documentation and a clear linkage of objectives to agencies and to a system of monitoring and appraisal by both national government and local communities.

One of the primary tools of DLG is integrated developmental planning (IDP) which is essentially a process whereby the aspirations of the community (public) are integrated with the knowledge, expertise and guidance of the local authority. This is a relatively new process for South African local government (municipalities undertook their first IDP cycle with the establishment of the 2002-2006 budget). In this paper, it is argued that, on the one hand, many of the participants of the IDP process do not understand the notion of developmental government and that Soft Systems Methodology (SSM) can be used to clarify and demystify the nature of the system and make it more accessible to participants. On the other hand, for the community to participate fully in IDP and to ensure that their priorities carry weight, a tool such as Multi-Criteria Decision Analysis (MCDA) is proposed to specify community criteria and to make explicit their levels of importance. The application of SSM also serves to deepen our understanding of the system that is DLG, its aspirations, abilities and limitations by relating a hypothetical model of government to the real world. (A product of this process will be the identification of indicators that are linked to what government would like to do, but which are realistically grounded in what government is actually able to do.) This process will also articulate those dimensions of poverty identified by communities and by national government to which local authorities are able to respond.

\section{Systems thinking and local government}

This paper is concerned with the issue of improving effective poverty intervention and proposes the development of a framework of local government within appropriate processes of measurement and control (indicators). Checkland (1993) lays out what he sees as problematic areas for the methods of rational science which led to the establishment of Systems Thinking as an alternative to the reductionist approach of traditional science. He cites the complexity of real world problems that have forced us to break massively dense issues down into smaller problems, often within separate disciplines. Unfortunately, however, systems as a whole frequently display different properties to those of their con-

\footnotetext{
2 "Developmental local government must deal with two elements concurrently. We must address massive poverty; the depth of this poverty cannot be underestimated. At the same time, we must sustain the areas of our country with 'first-world' infrastructure and institutions." — Gordham (1998)
} 
stituent parts, thus solutions to the sub-problems do not always solve the problem as a whole. Checkland also cites the difficulty of applying scientific methods to social science problems and problems of management in general where it has proved difficult to establish a body of well-behaved laws of behavior equivalent to those found in the natural sciences. Checkland argues that there is no convincing set of scientific expertise that is the backbone of management in the sense that physics and chemistry provide essential support for engineering. These difficulties have lead to the emergence of the systems approach, which tackles complex systems as entities rather than as the sum of their parts. Systems of government may be viewed as ultimate catch-alls for the set of complex problems of social science and management outlined by Checkland and therefore should provide fruitful ground for the systems approach. In summary, problems located within systems of governance tend to be complex in that they are often multi-player, multi-objective and multi-level (i.e. have local, regional, national perspectives).

A particular example of the systems approach is $\mathrm{SSM}^{3}$, a so-called 'problem structuring' approach which can be particularly useful to define the context, scope and nature of the issue being explored. It is frequently used to assist a group to reach a deepened understanding on a broad definition of a complex problem arena, its components and their interactions. It can also be used to determine where there are inconsistencies between intention and ability or between a conceptualised system and reality.

The SSM tool is often used in a workshop situation to promote debate between participant (groups of) persons. In fact, it is generally regarded (and intended to be used) as a participative tool (Checkland, 1988). However Checkland and Scholes (1990, p164) also state "If a study is done which happens to use SSM, then its use is likely to be very flexible, and at more than one level! Its value is then as an epistemology by means of which an analyst can make sense of the flux of project activity." SSM is used in this paper in precisely this way, in other words to allow the analyst to develop an understanding of the documentation circumscribing the functioning of developmental local government. This understanding might form a point of departure which could be developed further (and more realistically) with authorities responsible for local and regional planning and allocation of resources. At this point, however, the understanding developed through using SSM to sift through and categorise the legislation governing SSM has been used to provide a framework for monitoring and evaluation of DLG and for interacting with communities. The legislation puts in place certain duties and aims of DLG, but only provides for specific levels of functionality. The community express a number of needs, not all of which overlap with the functionality of the local authority to meet those needs. This paper relates a means of matching community identified needs to the powers and functions of local government and establishes a framework within which potential gaps or mismatches can be identified. It is believed that this approach can help foster better relations between communities and the different spheres of government.

\footnotetext{
${ }^{3}$ See, for example, Checkland and Scholes (1990) for a detailed explanation of the method.
} 


\subsection{Background documents}

A number of legal documents ${ }^{4}$ were consulted to assist in defining what it is that DLG is actually intended to achieve. The Municipal Systems Act (1998) defines the legal nature of a municipality, the necessary principles and processes to ensure universal access to affordable services, prescribes effective public participation, defines the powers and functions of a municipality, and articulates a framework for organisational change, performance management, financial control and accountability. The Municipal Structures Act (1998) also defines the categories and types of municipality and the appropriate division of powers and functions between them, as well as the establishment and regulation of electoral systems, internal systems, structures and office-bearers. The Constitution (1996) is the supreme law of the country and provides the foundation for a democratic, just and open society based on human rights and improved quality of life for all. The Constitution determines the overall objectives, developmental duties and powers and functions of municipalities.

\subsubsection{Aims and objectives of local government}

The following aims and objectives were summarised from the cited in this section documents. Note that although listed separately in the Constitution, there is considerable overlap between aims and objectives on the one hand and duties on the other.

- Provide for the social and economic upliftment of local communities (This activity is described in the Municipal Systems Act (1998) as to 'Empower the Poor'). In this regard municipalities should give priority to the basic needs of the community (this is also a developmental duty of the municipality, as listed in Section 153 of the Constitution (1996)).

- Provide universal access to essential services that are affordable to all and that are provided in a sustainable manner.

- Promote a safe and healthy environment.

- Remain financially viable. The municipality is required to finance its affairs through fees for services, surcharges, taxes, levies, duties, etc. and also to exercise credit control and debt collection.

- Encourage community involvement and participation.

\subsubsection{Duties of local government}

The following duties were summarised from the documents cited in this section:

- Use resources of the municipality in the best interests of the local community.

- Provide democratic and accountable government.

\footnotetext{
${ }^{4}$ The Municipal Systems Act (2000), The Constitution of the Republic of South Africa (1996) and The Municipal Structures Act (1998).
} 
- Encourage community participation.

- Strive to provide services in a financially and environmentally sustainable manner.

- Provide equitable access to services.

- Consult community on level, quality, range, impact and options of service.

- Promote and undertake development in the municipality.

- Promote gender equity.

- Promote a safe and healthy environment.

- Contribute (along with other spheres of government) towards the progressive realisation of sections 24 (healthy environment), 25 (security of tenure and access to land and property), 26 (adequate housing), 27 (access to health care, food, water and social security) of the Constitution (1996).

\subsection{An SSM approach to DLG}

SSM comprises the following notional stages, not all of which are necessarily included in a particular application:

- finding out about the problem arena,

- formulating root definitions of relevant systems,

- building conceptual models of component systems of purposeful human activity,

- comparing models with the real world, and

- taking action to improve the situation.

In this particular application of SSM the initial step was to plunge into building root definitions (although one could argue that the preceding sections of this paper establish a relevant problem context and milieu). The process of building a root definition consists of defining the clients, actors, transformation process, world view, owner(s) and environmental constraints (CATWOE) pertinent to DLG. Naturally most of these definitions could be made more meaningful by the actors within particular local authorities themselves. However, the material in the following two subsections are suggested as being consistent with the cited documentation governing DLG.

\subsubsection{Worldview}

Different world views result in different activities being emphasised, prioritised and made meaningful. Two different possible world views are listed here, namely:

- A view of DLG as a constitutional and legislative obligation (uses the legislation governing DLG, including the Constitution (1996), to distill information on the precise meaning of DLG). This is essentially the world view adopted in this paper. 
- The perspective of DLG as the implementation arm of the governments macroeconomic policy of Growth, Employment and Redistribution (GEAR) which focusses strongly on cutting government spending and encouraging investment

Each of the above views provides a different milieu or ethos within which the system of local government takes meaning and defines what is meant by 'effective.' Only the first (constitutional) view is adopted in this paper. However, the other world views may fruitfully be explored to ascertain

1. what differences in activities, prioritisations or inconsistencies become apparent using different world views, and

2. whether it is effectively possible to adopt all these views simultaneously or whether they are in some sense in competition with each other.

\subsubsection{Transformation}

The 'defining statement' of local government is developed by drawing on the relevant sections of the cited documents dealing with 'Aims and Objectives' as well as 'Duties' of local government.

DLG is a system to move progressively towards the social and economic upliftment of local communities; to ensure universal access to essential services that are affordable to all (and specifically the poor and disadvantaged); to actively engage communities in the affairs of municipalities of which they are an integral part, and in particular planning, service delivery, performance management, resource utilisation and organisational change; to empower the poor by providing an efficient, effective and transparent system of local administration as well as a framework for delivery of services that takes the needs of the poor into account, in order to achieve the overall social and economic upliftment of communities in harmony with their local natural environment. (Italicised text extracted directly from Act no 32 (2000).)

A more precise statement of this root definition that draws in all elements of the CATWOE mnemonic could be:

A community and state owned system, which under the following environmental constraints taken as the given

- Financial constraints to operation

- Legal and constitutional constraints to operation

transforms the input less socio-economically developed communities into the output more socio-economically developed communities by means of the following major activities:

- Provision of universal access to essential services that are affordable to all (and specifically the poor and disadvantaged). 
- Active engagement of communities in the affairs of municipalities of which they are an integral part, and in particular planning, service delivery, performance management, resource utilisation and organisational change.

- Empowerment of the poor (by providing an efficient, effective and transparent system of local administration).

- Provision of a framework for delivery of services that takes the needs of the poor into account.

The transformation being carried out by these actors:

- Councillors, council office bearers, council employees.

- Community Based Organisations.

- Other spheres of government including other local authorities where applicable.

And directly affecting the following beneficiaries ond/or victims:

- The 'community' (Business, CBOs, NGOs, ratepayers, residents, etc.).

- Provincial and National government.

The world view which makes this system meaningful is that which is shaped by the Constitution (1996) and the Municipal Systems Act (2000) and as articulated in the following phrase from Preamble to the Municipal Structures Act (1998): DLG ... "in which municipalities fulfill their constitutional obligations to ensure sustainable, effective and efficient municipal services, promote social and economic development, encourage a safe and healthy environment by working with communities in creating environments and human settlements in which all our people can lead uplifted and dignified lives."

An immediately apparent aspect of this root definition is that it suggests that 'the poor' are intended to have a special relationship with local government and that local government is indeed intended as a frontline advocate of 'the poor.' A very broad schematic for the system, which fits the above definition, is given in Figure 1. This is the beginning of a 'rich picture,' by which is meant 'the expression of the problem situation compiled by an investigator, often by examining elements of structure, elements of process and the situation climate" (Checkland, 1993).

Also clear from the root definition is that there is a need to define who 'the community' are and to articulate more clearly what is meant by consulting with each of the constituent groups and what their interrelationships are.

\subsection{Outcomes of the SSM process}

The SSM approach articulates the following aspects of DLG within a specific world view:

- the roleplayers involved in the system of DLG (actors, clients and owners), 


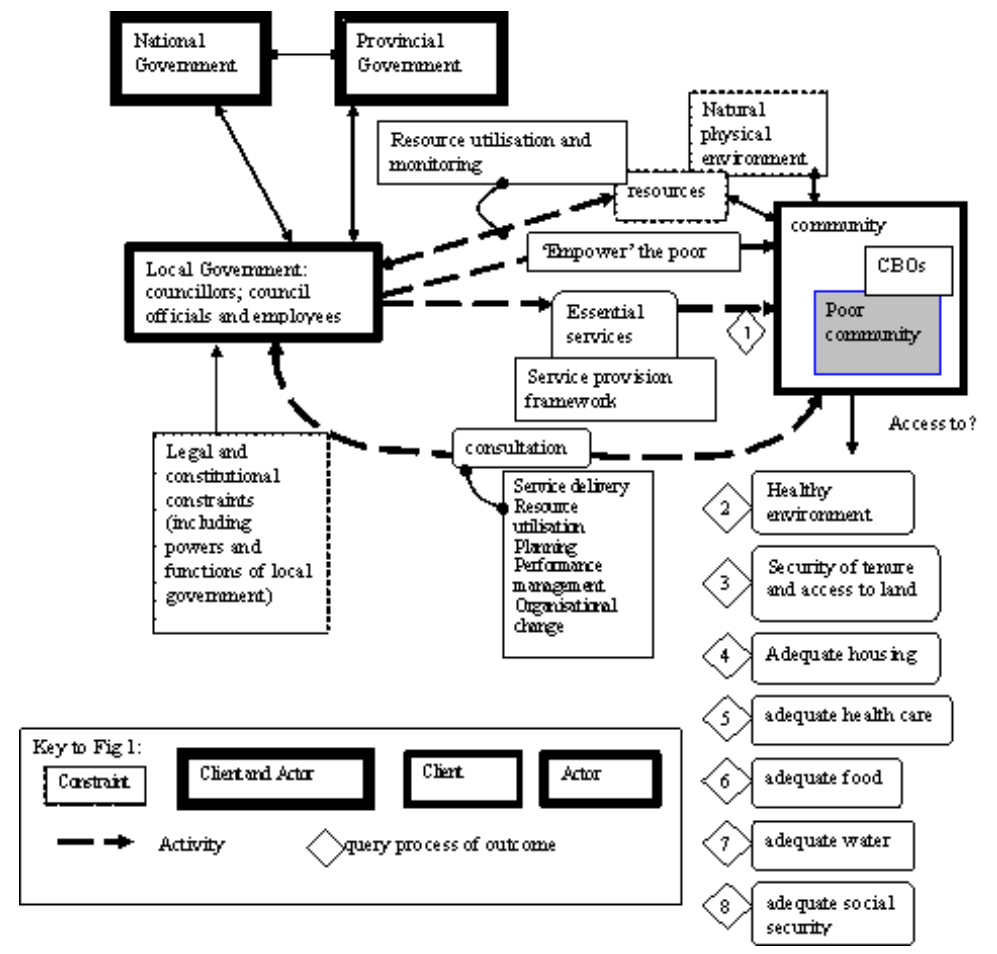

Figure 1: A rich picture of developmental local government.

- the activities undertaken to bring about a process of transformation,

- the constraints to this process taken as given, and

- the nature of the transformation that DLG is endeavouring to achieve.

The picture of DLG in Figure 1 has been augmented by diamonds which represent possible query points. These show where an indicator could be used to determine the extent to which the municipality is, for example, providing or enhancing access to adequate housing, health care, food, etc., and where appropriate for that level of municipality. One can also query the resource utilisation of the municipality (appropriate use of income, collection of debts and other revenue, etc.) as well as the sustainability of the resource usage in terms of the physical environment and in financial terms.

This very rough outline of local government interaction with the community may be expanded to elaborate the nature of the relationships with other spheres of government and particularly to examine the specific activity systems mentioned in the root definition above. In other words the links between service provisions, economic and social upliftment, financial and environmental sustainability, and community consultation may be developed. This involves developing root definitions of the different activity systems and unpacking what is meant by 'empower the poor' or 'efficient, effective and transparent frameworks of service delivery.'

The articulation of the constraints, particularly the budgetary and resource constraints, makes concrete the extent to which the overall objectives (of transformation) are, in fact, 
achievable. It is important to articulate that any decision making or resource allocation is done within the context of a fixed overall budget.

Further apparent in this rich picture is that there is very little focus on the economic aspects of development: of job creation and growth stimulation. Examining DLG under the world view of GEAR would lead to an emphasis on other government documentation around directives to local government which tend to emphasise the economic development issues more strongly

\subsection{Indicators}

The query points in Figure 1 show natural places for indicators to measure the intended outcomes of DLG. The approach of SSM is to measure whether a transformation is successful or not by measuring whether (1) the means actually achieves the intended output; (2) whether it does so using minimum resources and (3) whether it achieves the longer term goal of the transformation (i.e. The ' $Z$ ' part of the definition of the system: 'A system to do $\mathrm{X}$ by $\mathrm{Y}$ in order to achieve Z'.) Some suggestions of possible indicators in keeping with this line of enquiry are shown below:

\section{Indicators ${ }^{5}$ of 'Essential Services:'}

(a) Effectiveness: Incidence of water borne disease.

(b) Efficiency: New service connections per unit of budget spent.

(c) Efficacy: Number of new water connections.

2. Indicators of 'Healthy Environment:'

(a) Effectiveness: Incidence of pulmonary disease; incidence of diseases relating to occupational hazards.

(b) Efficiency: Cost of unit change in, for example, levels of pollutants.

(c) Efficacy: Levels of noxious gasses / water pollutants.

3. Indicators of 'Adequate Housing:'

(a) Effectiveness: Rates of TB (due to damp housing); rates of crimes related to overcrowding.

(b) Efficiency: Cost per house built.

(c) Efficacy: Proportion of population housed in permanent structures; square metre area per person accommodated.

4. Indicators of 'Adequate Health Care:'

(a) Effectiveness: Mean life expectancy; maternal death rates.

(b) Efficiency: Waiting time to treatment for common ailments; cost per patient treated.

\footnotetext{
${ }^{5}$ Checkland and Scholes (1990) suggest the following definitions. Effective: achieves higher order aims; Efficacious: producing the desired output (doing the required job); Efficient: minimum use of resources.
} 
(c) Efficacy: Proportion of, for example, AIDS or TB or malaria patients receiving treatment; patients treated per clinic; clinics per area unit.

The above indicators are given as hypothetical examples only. They could also be disaggregated, for example, by gender and age group, where appropriate. Naturally the precise nature of the indicators chosen depends on the issues of the particular community (prevalent diseases, social and environmental problems, age and socio-economic profile, etc.) and on the availability of adequate data.

\section{Prioritisation of community needs: A case study in Pniel}

An important aspect of DLG relates to the consultation process between the community and the local authority. It is an obligation of local authorities (see Republic of South Africa, 2000) to organise community participation processes so as to facilitate the flow of information between the two groups. However, this consultation process will lack teeth unless there are specific tools which assist the community to not only articulate, but also to prioritise their needs, and have them duly noted and recorded. Unless there exists some record of the relative levels of importance that the community attaches to specific issues or criteria, the local authority can side-step the directives of the community when it comes to budget allocations and planning. Once community-based relative levels of prioritisations have been recorded, communities may investigate whether local authority spending is, in fact, in accordance with these prioritisations and hold local authorities accountable to defend their actions.

An approach to the task of prioritizing needs is to use multi-criteria decision analysis (MCDA) tools in workshops with community representatives. MCDA can broadly be described as a school of approaches which takes explicit account of multiple conflicting criteria / objectives, as well as values, and which attempts to aid decision or policy making by structuring the decision domain. A more detailed account of specific MCDA methods is included in Belton and Stewart (2002). Current municipal practices with regard to budget prioritization processes show limited use of formal tools such as MCDA. Olivier et al (2002), in an unpublished working paper, show some seven, out of a total of a hundred and thirty municipal 1999/2000 budgets reviewed, used an MCDA-like approach to their public participation and budgeting process. The authors concluded that, in municipal budgeting processes, prioritization processes, tools and methodologies were generally poorly developed and largely ad hoc, and that a frequent consequence of this was a mismatch between strategic plans and budgets.

An MCDA approach based on value functions was used in this case study to assist a community with respect to establishing a hierarchy of objectives or needs. This hierarchy was weighted to reflect community preferences or prioritisations. To ensure that the assigned weightings were meaningful they were assigned within the context of different possible alternatives for capital spending, and within the scope of available budget. Stewart (1992) points out that determining the decision context for a multi criteria problem is particularly important and advocates for a 'swing weight' approach to allocating criterion weights. "The fundamental principle is that the weights have a natural implicit trade- 
off interpretation, that can only be assessed in the context of the ranges of the options available" (Stewart, 1992).

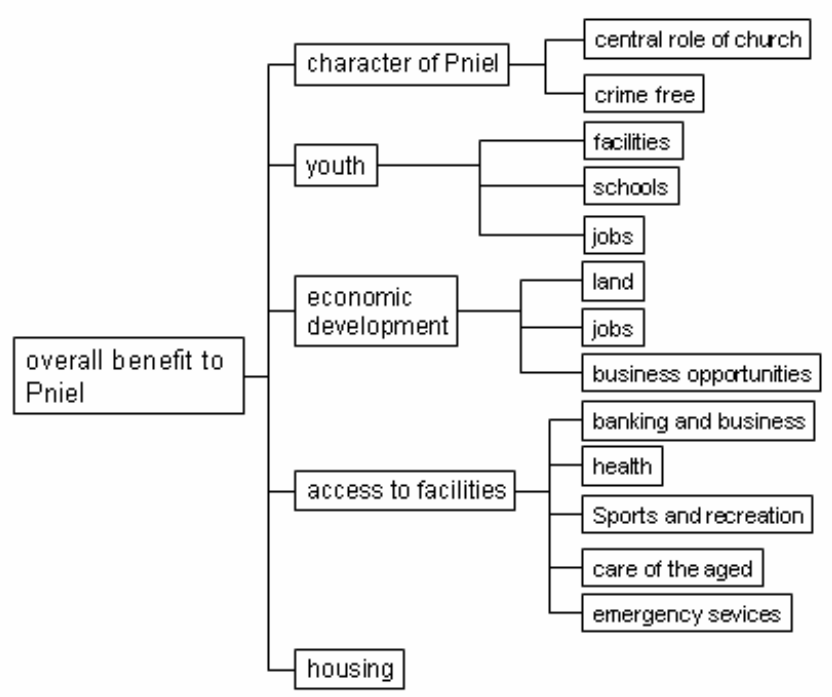

Figure 2: Value tree showing community assessments of need in Pniel.

This case study was undertaken with the Pniel ${ }^{6}$ community of the Western Cape, as part of a $\mathrm{SANPAD}^{7}$ funded project, and illustrates how an MCDA model can summarise and articulate community issues and needs. At the time of the study, the community of Pniel had their own separate municipality, later to be amalgamated as part of the larger Stellenbosch municipality. The hierarchy of criteria given in Figure 2 represents the issues which the Pniel community, including councillors and officials, believed should drive the budget. Around 30 members of the Pniel community attended all or part of a series of four workshops to derive the hierarchy and associated weights. Participants represented the Pniel Town Council and officials, the Ratepayers' Association, Pniel sports clubs, a housing association, the town's museum, the Pniel Civic Association, the business sector, the Congregational Church, the agricultural sector, the tourist sector and the primary school.

The criteria were formulated after an initial workshop in which participants recorded their views of the strengths, weaknesses, opportunities and threats facing Pniel. These were grouped and summarised into a number of criteria that participants felt should drive the budget allocation with respect to development in Pniel. In keeping with the approach proposed by Belton and Stewart (2002) the chosen set of criteria were judged to meet the

\footnotetext{
${ }^{6}$ The town of Pniel is situated on the slopes of the Helshoogte pass between Franschhoek and Stellenbosch in the Western Cape. It has a population of approximately 2400 . Originally a mission station, the Congregational Church still has a strong influence in the community. Major community based organisations are grouped around sport, the church and schooling. Most employment is these days found outside the town.

${ }^{7}$ South Africa Netherlands Project for Alternatives in Development. Project FARCODE (2000-2002) is a SANPAD funded project which aims to develop tools for assisting the budgeting processes of municipalities using MCDA tools.
} 
following requirements:

- Value Relevance: the criteria can be linked to higher level goals.

- Understandability: there is shared understanding amongst participants of the criteria and their relevance.

- Measurability: the criteria are able to be measured or evaluated in some sense.

- Non-redundancy: each conceptual community value or issue can be mapped on to one criterion only (to avoid double counting).

- Judgemental independence: preferences with respect to one criterion do not depend on the level of another criterion.

- Balancing completeness and conciseness: there are sufficient criteria to capture (what the community consider to be) all relevant issues and aspects but the model is not overly detailed.

- Operationality: the model is usable within the context and constraints of the decision problem at hand.

\subsection{The process of generating a community value tree}

The following process of generating criteria that reflected the needs of the Pniel community was followed:

1. Identification of stakeholders and planning of group workshops.

2. Stakeholders chose criteria and sub-criteria using an MCDA approach and thereby created a 'value tree' for the community (a hierarchy of criteria representing community needs).

3. A list of proposed capital projects ${ }^{8}$ was drawn up and each of the projects was evaluated (scored) relative to each of the identified criteria. Stakeholders determined the relative weights (levels of importance) of the criteria.

4. Stakeholders evaluated the proposed capital projects using the value tree and explored the sensitivity of their inputs (project scores and criterion weights).

5. Stakeholders used the value tree to propose possible indicators that may be used to monitor the effective use of the budget.

\footnotetext{
${ }^{8} \mathrm{~A}$ capital project is one which was funded from discretionary funding and not from the part of the budget allocated to service provision, salaries, wages and running expenses of the municipality.
} 


\subsection{Workshop cycle}

The following cycle of workshops and feedback formed the basis of the work with the Pniel community:

- Consultations held with town officials to obtain preliminary documents outlining existing consultations with the community and contact details of interested and affected parties.

- Notice and advertisement of general public meeting(s) given to which, in addition, key community representatives, councillors and officials were specifically issued invitations to attend.

- Agenda of workshop 1: Identify budget criteria and establish a value tree for the community. The value tree establishes the hierarchy of criteria which are deemed to affect the overall well being of the community and which should be reflected in the budget.

- Results of workshop 1 were fed back to the wider community for approval.

- Agenda of workshop 2: Identify a list of possible capital budget-funded projects; Determine the relative importance of each of the criteria identified in workshop 1.

- Results of workshop 2 were fed back to the wider community for approval.

- Agenda of workshop 3: Score each of the proposed projects with respect to each of the criteria identified in workshop 1. Sensitivity of the input was explored and scores and weights were adjusted as appropriate.

- Results of workshop 3 were fed back to the wider community for approval.

- Agenda for workshop 4: Use the value tree to propose indicators for each of the criteria (where appropriate) and discuss sources of data.

- Indicators proposed were disseminated to the wider community.

- Community accepted or modified the value tree and indicators.

\subsection{Decision making tools to facilitate community involvement}

The specific MCDA tool applied in the Pniel workshops is known as Visual Interactive Sensitivity Analysis (VISA, developed by Valerie Belton of University of Strathclyde in 1986). This computer based technique allows users to explore the sensitivity of their choices with regard to criteria, scores and weights. A description of the use of this approach is given in Belton and Vickers (1990). The measuring tool applied in the workshops is referred to as a 'thermometer' scale and it assesses the relative 'value' of each alternative on a scale between BEST (usually nominally assigned a value of 100) and WORST (nominally $0)$. Alternatives are arranged on this scale by workshop participants in such a way that the gaps between two alternatives reflect the benefits gained/lost in moving from one alternative to another, in terms of a specific criterion. The numeric value of the position 
of an alternative on the thermometer is taken as a surrogate of its relative worth with respect to the given criterion, but does not (necessarily) have absolute meaning.

A simple direct weighting procedure was used. Although a formal swing weighting technique was not used, participants were reminded to take cognisance of the differential between the lowest and highest rated alternative for each criterion (a difference nominally given an allocation of 100 points in each case). Belton (1985) states that "The weight assigned to a criterion must reflect the significance of this differential as well as the importance of the criterion." The weights were allocated by the following procedure: Respondents selected the most important criterion in the context of the proposed list of projects. This criterion was then allocated a weight of 100 and respondents then assigned weights to the remaining criteria relative to this (maximum) value.

The VISA software allows users to explore the sensitivity of their inputs (criteria weights and project scores) to ensure that they feel comfortable with their chosen responses and the effects of changes to these values on the outcomes. With a reasonably skilled facilitator, VISA can accommodate a wide range of abilities, backgrounds and levels of sophistication. It does not demand any mathematical skills from the users as all user inputs (scores and weights) can be allocated using pictorial representations and does not impose anything more complex than a weighted average as a mathematical structure. Moreover, users need only aggregate measurements to a level to which they feel it is meaningful and so are not forced to reduce all information to a single measure.

In the case of the Pniel project, the computer software was only introduced into the process at the third workshop so as to allow participants to explore the value tree and its implications. The first two workshops were run with a facilitator simply grouping the participants' responses on flipcharts.

\subsection{Outcomes of the Pniel workshops}

The value tree shown in Figure 2 emerged at the end of the workshop series after a process of sensitivity analysis and community review. The value tree shows the main criteria and (where relevant) the sub-criteria that should be used to drive decision making about budgetary allocations in Pniel. The levels of importance (weights) attached to each of the criteria are shown in Table 1.

The weights displayed in Table 1 show that the five major criteria in Pniel relate to:

- The 'unique character' of Pniel: a nebulous criterion relating (equally) to the strong relationship of the community with the Church and their mission-station roots, and to the fact that Pniel is relatively safe and crime-free.

- Issues relating to the youth, mainly job opportunities for the youth, but also facilities (social, recreational, training) and schools. There are no high schools in Pniel and the youth tend to leave to go to high school elsewhere and many never return as there are few jobs.

- Economic Development: of equal importance are land, jobs and business opportunities. 


\begin{tabular}{|c|c|c|c|}
\hline Major criterion & $\begin{array}{l}\text { Weight } \\
\text { of major } \\
\text { criterion }\end{array}$ & Sub-criterion & $\begin{array}{l}\text { Weight } \\
\text { of sub- } \\
\text { criterion }\end{array}$ \\
\hline \multirow{2}{*}{ Unique character of Pniel } & \multirow{2}{*}{100} & Central role of the Church & 100 \\
\hline & & Safe environment & 100 \\
\hline \multirow{3}{*}{ Youth } & \multirow{3}{*}{60} & Facilities & 45 \\
\hline & & Jobs & 100 \\
\hline & & Schools & 20 \\
\hline \multirow{3}{*}{ Economic development } & \multirow{3}{*}{100} & Land & 100 \\
\hline & & Jobs & 100 \\
\hline & & Business opportunities & 100 \\
\hline Housing & 40 & & \\
\hline \multirow{5}{*}{ Access to facilities } & \multirow{5}{*}{25} & Banking \& shopping & 100 \\
\hline & & Sports \& recreation & 10 \\
\hline & & Care of the aged & 50 \\
\hline & & Emergency facilities & 15 \\
\hline & & Health facilities & 45 \\
\hline
\end{tabular}

Table 1: Levels of importance of identified budget criteria in Pniel.

- Housing: there is no land available in Pniel for more housing and this is also causing people to move elsewhere.

- Access to facilities: There are no banks in Pniel and only small convenience stores which are relatively expensive, as is transport to neighbouring towns. Lack of shopping and banking facilities costs time and money to the people of Pniel and was rated the most important in terms of 'facilities.' Health and care of the aged facilities were considered the next most important issues. Emergency, sports and recreation facilities were considered relatively unimportant as Pniel has well developed sporting facilities in general and makes use of the emergency facilities of the nearby town of Stellenbosch.

\subsection{Comments on the MCDA process}

The MCDA exercise assisted participants to group and prioritise the needs and aspirations for their community. It provided an opportunity for different interest groups to articulate their similarities and differences around the issue of budget allocation. The strength of the methodology used is in its sensitivity analysis, which allows participants to explore the effects of different weighting systems, different scoring systems and different value trees. The development of a hierarchy of criteria (needs) or a value tree provides a template for community based indicators. Criteria such as 'Central role of the Church' still need to be unpacked to see what concrete and measurable issues can be identified. Several possibilities exist for monitoring 'safe environment' such as crime statistics and measures of physical environmental quality (such as levels of air pollution). Crime statistics can, in 
particular, be disaggregated to monitor the safety of children, women, the aged people and other vulnerable groups. These possible indicators would need to be explored in a further workshop with the community to agree on appropriate ways to proceed with monitoring and evaluation. Statistics such as proportion of school leavers who find work in Pniel (and outside), unemployment rates in Pniel (disaggregated by age and gender), rates of delinquency amongst the youth (a potential concern) and housing waiting lists have been suggested to be linked to the value tree.

The approach prescribed in the documentation on Integrated Development Planning assumes that the list of available options (alternatives) for local government intervention remains open throughout the process and that the budget available is not fixed (applications can be made for ad hoc funding from different sources, given adequate motivation). These provide further challenges and require that the MCDA approach proposed here be further developed and modified to cope with these conditions.

\section{Discussion: Synthesising community prioritisations and national directives with respect to poverty}

The application of problem structuring methods, such as SSM, to help interpret the legislation surrounding DLG and translate it into effective local government actions has been discussed in this paper, particularly with respect to poverty relief. It is also suggested that SSM is a useful tool that local authorities could use with an external facilitator to explore how to implement DLG within their own municipality. It has been used here by an analyst/facilitator to create a framework within which to locate community needs relative to local authority functions and jurisdictions. Thus it can be used to specifically register which functions of DLG are able to be fulfilled by that authority (and how) and which are not (and what other mechanisms need to be put in place to facilitate the fulfilment of the latter).

An important aspect of DLG emerged as community consultation and it is proposed that a tool such as MCDA be used to concretise community aspirations and prioritisations into a form with which local authorities can effectively work. In a sense these two processes (SSM and MCDA tools) represent approaches to dealing with two different level demands on local authorities: those that come from national government and those that emerge from the local community.

It is suggested that both the SSM exercise and the MCDA community prioritisation exercise can lead to the identification of key indicators of poverty and of local government performance in general.

\subsection{Synthesis of national and local imperatives}

The matrix in Figure 3 shows the degree of compatability between the issues identified as important by the Pniel community and the local government objectives specified by the cited national level legislation. Needs such as 'provision of jobs', 'facilities for the youth' and 'business opportunities' have been matched to the hold-all term of 'empower the poor.' 
It would remain to be seen how individual authorities interpret this imperative and what actions they envisage as being of relevance. Of importance is the fact that municipalities may only operate in the sphere of their legislated powers and functions. There thus needs to be a matching of not only local aspirations to national objectives for municipalities but also a corresponding match to a relevant municipal power to perform a function in this area.
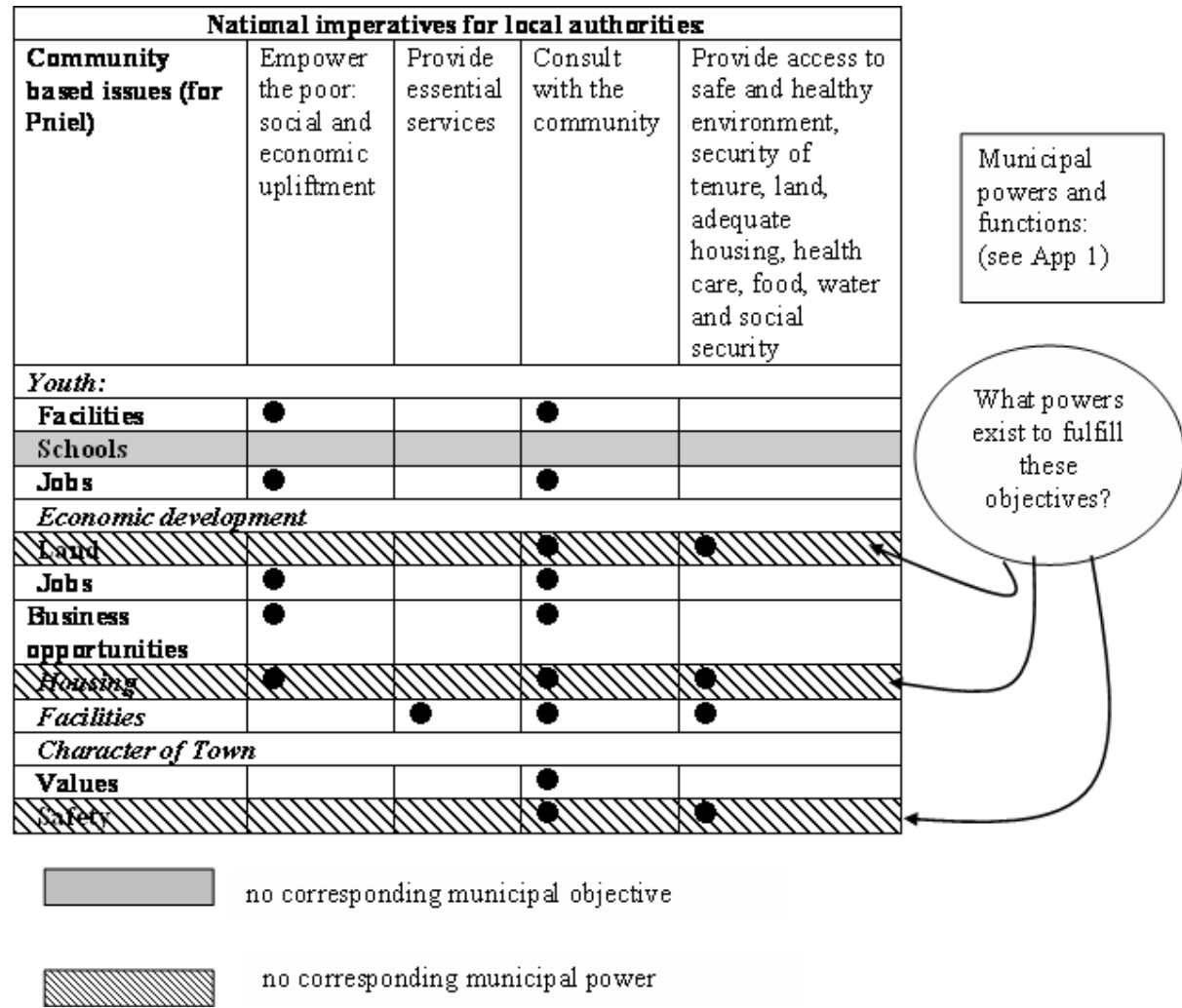

Figure 3: Matrix showing the interaction between community aspirations and local government objectives.

There may also be a tension between short term needs (possibly those issues that are most immediate in the minds of members of the community) and long term needs (which may not be currently apparent, but which may become far more serious problems if not dealt with now). The local authority may need to draw on expert advice to inform communities on time periods available to tackle problems (and their associated costs). There may need to be a period of mutual education and advocacy between the local authority and the community to establish the extent to which the budget is used to tackle short term as opposed to long term issues.

Some of the community aspirations may involve non-governmental or private sector organisations. The local authority may then need to find a way to facilitate a need being met (such as a need for banking facilities) that involves the provision of a service by the private sector.

There may well be community aspirations for which there is no corresponding municipal 
objective and/or municipal functionality. The powers and functions allocated to local government are listed in the Appendix. In terms of this list, there is no apparent functionality for local authorities to, for example, "provide access to land [or] adequate housing." 9 In other words there may be a mismatch between (i) community expectations of local government, (ii) national objectives for local government and (iii) actual functional authority of municipalities to be effective in achieving either of the aforementioned.

It is important that these issues are highlighted and that community expectations are directed to the appropriate sphere of government and effective linkages established between the community and the organ of governance responsible for dealing with non-municipal level functions of state. (As is the case with the Pniel community identified need for schools in Figure 3)

The matrix in Figure 3 is a simple vehicle for analysing the effectiveness of a local authority in terms of both (i) meeting the needs of the community and (ii) fulfilling constitutional obligations.

\subsection{Indicators and the budget}

The aim of the exercise in Pniel was to develop a hierarchy of community needs which could be prioritised and linked to the budgeting process. The indicators that arise from this process are vital tools that may be used to ensure that the community have some handle on the budgeting process and can monitor the effective use of funds in their area. The exercise in Pniel was only applied to the capital budget (specifically that part of the capital budget that is uncommitted and not dictated by external funding marked for specific purposes). Once community-based organisations are more fully involved in planning processes (as envisaged by the dictates of the legislation), then it may be possible to extend this prioritisation process to the wider budgeting process in shaping the future structure and functioning of the authority.

While the matrix in Figure 3 is a tool to indicate the compatability between local expectations and government vision, carefully chosen indicators can be used to assess how effectively the local authority tackles the identified issues.

\subsection{Further developments}

It is suggested that the way forward to operationalise the two exercises described in this paper will be to:

- Agree (with all stakeholders) on a definition of poverty. This is important, because there may well be aspects of poverty that local authorities do not or cannot address.

\footnotetext{
${ }^{9}$ It should, however, be noted that in terms of the Constitution (1996), national and provincial government must assign to a local authority the power to administer any matter which, although normally regarded as a provincial or national function, would a) be most effectively administered locally and b) the local authority has the capacity to administer. Moreover, it is further stated in the Constitution (1996) that "A municipality has the right to exercise any power concerning a matter reasonably necessary for, or incidental to, the effective performance of its functions." This appears to give wide reaching latitude for municipalities to adopt powers appropriate to the achievement of their objectives.
} 
For example, there is no reference in our rich picture to education. Also, reference is made to 'access to security of tenure and to adequate housing,' but for many communities the local authority will not be the one dealing with housing issues directly. This also implies that there is a need to define what activities are envisaged by the term "provide access to..."

- Link each department (within the local authority structure) to the identified duties, aims and objectives of local government. This step will promote a multidepartmental approach to issues such as health that may involve the departments dealing with housing and the physical environment.

- Agree (with community, officials and councillors) on indicators to measure each of these duties, aims and objectives.

- Link the specific indicators identified and attached to the community's value tree to the relevant departments within the municipality (again ensuring that, where appropriate, more than one department takes responsibility for an indicator or set of indicators).

The above two sets of indicators form a set of externally imposed (nationally directed) and a set of locally crafted indicators. It is also necessary to:

- Review whether all aspects of the agreed definition of poverty are covered by the indicators, by involving the community and advocacy groups, as well as the local authority.

- Agree with stakeholders on data sets to measure the indicators.

Other important considerations to this process include:

- Allowing for disaggregation by gender, age or any identified vulnerable group.

- Considering selection of a number of alternative measures for a short period and then examining the set for robustness, sensitivity, the ability to detect vulnerability to poverty and to distinguish between transient, chronic or permanent poverty.

- Considering, also, the need to track inequality in terms other than monetary (such as education, mortality, morbidity or prevalence of social problems).

\section{Conclusions}

This paper contains a description of how two different analytical tools can be used to help structure and prioritise community needs and aspirations within a DLG context. SSM can be a useful tool in developing a locally relevant interpretation of DLG and a framework for addressing community needs. MCDA can assist communities to prioritise their needs and to choose between competing alternative projects to address these needs. A synthesis of the two approaches allows for a framework within which one can assess which 
community aspirations are being (or are able to be) addressed by the local authority. The unaddressed aspirations may need to be taken up by undergoing a similar exercise with the relevant national and provincial authorities so that communities have more transparency and understanding of the processes and structures which are available for development.

\section{References}

[1] Belton V, 1985, The use of a simple multiple criteria model to assist in selection from a shortlist, Journal of Operational Research Society, 36(4), pp. 265-274.

[2] Belton V \& Vickers S, 1990, Use of a simple multi-attribute vale function incorporating visual interactive sensitivity analysis for multiple criteria decision making, pp. 319-334 in BANA E COSTA CA (ED), 1990, Readings in multiple criteria decision aid, Springer, Berlin.

[3] Belton V \& Stewart TJ, 2002, Multiple criteria decision analysis: An integrated approach, Kluwer Academic Publishers, Dordrecht.

[4] Checkland P, 1988, Soft systems methodology: An overview, Journal of Applied Systems Analysis, 15, pp 27-30.

[5] Checkland P \& Scholes J, 1990, Soft systems methodology in action, Wiley, Chichester.

[6] Checkland P, 1993, Systems thinking, systems practice, Wiley, Chichester.

[7] Gordham P, 1998, White paper on local government parliamentary hearings, [Online], [Cited: 10 November 2005], Available from www.dplg.gov.za/ documents/wpaper/wpindex/htm

[8] Henderson H, 1991, Paradigms in progress. Life beyond economics, Berrett-Koehler Publishers, San Francisco (CA).

[9] Olivier A, Van den Honert RC \& Scott L, 2002, Fair allocation of local government funds through public participation: Linking the IDP with budgets through the application of multi-criteria decision analysis in some western cape municipalities. Unpublished working paper of SANPAD project FARCODE.

[10] PARnell S \& Poyser M, 2002, The value of indicators as a tool of local government, pp. 251-261 in Parnell S, Pieterse E, Swilling M \& Wooldrigde D (Eds), Democratising local government, the South African experiment, UCT Press, Cape Town.

[11] Republic of South Africa, 1996, Act no 108, The Constitution of the Republic of South Africa. Government Printer, Pretoria.

[12] Republic of South Africa, 1998a, Act no 117, Local government: Municipal structures act, Government Gazette no 19614. 
[13] Republic of South Africa, 1998b, White Paper on Developmental Government, Government Gazette no 18739.

[14] Republic of South Africa, 2000, Act no 32 of 2000, Local government: Municipal systems act, Government Printer, Pretoria.

[15] Sen A, 1981, Poverty and famines: An essay on entitlement and deprivation, Oxford University Press, New Delhi.

[16] Stewart TJ, 1992, A Critical survey on the status of multiple criteria decision making theory and practice, OMEGA - The International Journal of Management Science, 20(5/6), pp. 569-586.

[17] Thomas V, Dailami M, Dhareshwar A, Lopez RE, Wang Y, Kishor N \& Kauf K (Eds), 2000, The quality of growth, A World Bank Publication, Oxford University Press, New York (NY).

[18] World Bank, 2001, World development report 2000/2001. Attacking poverty, Oxford University Press, New York (NY). 


\section{Appendix: Municipal powers and functions}

Full list of municipal powers and functions (loosely grouped according to the aims and objectives of local government):

- Provision of a safe and healthy environment:

Air pollution; Building regulations; Noise pollution; Traffic and parking; Childcare facilities; Municipal health services; Cemeteries, funeral parlours and crematoria; Cleansing; Facilities for the accommodation, care and burial of animals; Licensing of dogs; Licensing and control of undertakings that sell food to the public; Markets; Municipal abattoirs; Pounds; Refuse removal, refuse dumps and solid waste disposal.

\section{- Provision of essential services:}

Electricity and gas reticulation; Firefighting services; Stormwater management systems; Water and sanitation services; Street lighting.

\section{Transport:}

Municipal airports; Pontoons, ferries, jettys, piers and harbours; Municipal roads; Municipal public transport.

\section{- Social and economic upliftment:}

\section{Employment issues:}

Local tourism; Municipal public works; Street trading.

\section{Facilities for the public:}

Beaches and amusement facilities; Local amenities; Local sports facilities; Municipal parks and recreation; Public places.

\section{Regulatory:}

Municipal planning; Control of undertakings that sell liquor to the public; Fencing and fences; Control of public nuisances; Billboards and the display of adverts in public places; Trading regulations. 